\title{
Just ONE
}

\section{SHERRYL CLARK}

see this arm, the ulna, the radius,

the elbow joint and humerus

the way it swings from your shoulder

like a well-oiled hinge

see the muscles, the tendons

the flexing and spreading of your fingers

the fist you can make

tight and hard and angry

see that skull, its hard carapace

its brow and rounded bone

the hollows for eyes and nose

those two neat rows of teeth

and behind it all, the brain

and you with your fist

holding onto it tight

nursing it

sore knuckles bruised skin

and over there

the skull on the ground

leaking, the brain dying

and you can never take back what

your fist did

what you did

you and your addled brain.

floating, a thick sponge

of memories and functions and life

and now we have a fist

and a skull, fist on skull,

fist smacking skull—smack

fist crunching cracking crippling skull

and a brain smashing

bouncing exploding 